\title{
Protective effects of probucol on Ox-LDL-induced epithelial-mesenchymal transition in human renal proximal tubular epithelial cells via LOX-1/ROS/MAPK signaling
}

\author{
BING BING ZHU $^{1 *}$, HAO WANG $^{1 *}$, YANG FENG CHI $^{1}$, YUN MAN WANG ${ }^{1}$, XING MEI YAO $^{1}$, SHUANG LIU $^{1}$, \\ HUILING QIU ${ }^{1}$, JI FANG ${ }^{1}$, PEI HAO YIN ${ }^{1}$, XUE MEI ZHANG ${ }^{2}$ and WEN PENG $^{1}$ \\ ${ }^{1}$ Department of Nephrology, Laboratory of Renal Disease, Putuo Hospital, Shanghai University \\ of Traditional Chinese Medicine, Shanghai 200062; ${ }^{2}$ Department of Pharmacology, \\ School of Pharmacy, Fudan University, Shanghai 201203, P.R. China
}

Received November 7, 2016; Accepted September 19, 2017

DOI: $10.3892 / \mathrm{mmr} .2017 .7935$

\begin{abstract}
Oxidized low-density lipoprotein (Ox-LDL), as a strong oxidant, results in renal injury through multiple mechanisms. The aim of the present study was to determine the injury effects of Ox-LDL and the potential protective effects of the antioxidant reagent probucol on epithelial-mesenchymal transition (EMT) in human renal proximal tubular epithelial cells (HK-2) and to further explore the role and interrelation of lectin-like oxidized low-density lipoprotein receptor-1 (LOX-1), reactive oxygen species (ROS) and mitogen-activated protein kinase (MAPK) pathway. In the present study, concentrations of $0-100 \mu \mathrm{g} / \mathrm{ml}$ Ox-LDL were used to induce HK-2 cell EMT. Then, probucol $(20 \mu \mathrm{mol} / \mathrm{l})$ and the LOX-1 inhibitor, polyinosinic acid $(250 \mu \mathrm{g} / \mathrm{ml})$, were also used to pretreat HK-2 cells. Intracellular ROS activity was evaluated using the specific probe 2',7'-dichlorodihydrofluorescein diacetate (DCFH-DA). Concentration of nitric oxide (NO) was determined using a biochemical colorimetric method. Expression of E-cadherin, $\alpha$-smooth muscle actin (SMA), LOX-1, NADPH oxidase 4 (NOX4), cytochrome b-245 $\alpha$ chain (p22phox), extracellular signal-regulated kinase (ERK), and p38 MAPK protein levels
\end{abstract}

Correspondence to: Professor Wen Peng, Department of Nephrology, Laboratory of Renal Disease, Putuo Hospital, Shanghai University of Traditional Chinese Medicine, 164 Lanxi Road, Shanghai 200062, P.R. China

E-mail: pengwen_01@vip.sina.com

Professor Xue Mei Zhang, Department of Pharmacology, School of Pharmacy, Fudan University, 826 Zhangheng Road, Shanghai 201203, P.R. China

E-mail: xuemzhang@fudan.edu.cn

${ }^{*}$ Contributed equally

Key words: epithelial-mesenchymal transition, oxidized low-density lipoprotein, probucol, lectin-like oxidized low-density lipoprotein receptor-1, mitogen-activated protein kinase pathway were examined by western blotting. The results revealed that Ox-LDL induced the expression of LOX-1 and $\alpha$-SMA and reduced the expression of E-cadherin in a dose-dependent manner, and these effects were inhibited by polyinosinic acid or probucol pretreatment. Stimulation with $50 \mu \mathrm{g} / \mathrm{ml}$ Ox-LDL induced the expression of NOX4 and p22phox and increased intracellular ROS activity, but NO production in the cell supernatants was not affected. The Ox-LDL-mediated increases in Nox4 and p22phox expression and in ROS activity were inhibited by probucol pretreatment. Further investigations into the underlying molecular pathways demonstrated that ERK and p38 MAPK were activated by Ox-LDL stimulation and then inhibited by probucol pretreatment. The findings of the present study therefore suggest that Ox-LDL induced EMT in HK-2 cells, the mechanism of which may be associated with LOX-1-related oxidative stress via the ERK and p38 MAPK pathways. Notably, pretreatment with probucol inhibited the Ox-LDL-induced oxidative stress by reducing the expression of LOX-1, and blocked the progression of EMT.

\section{Introduction}

Epithelial-mesenchymal transition (EMT) of renal proximal tubular epithelial cells in adult kidneys is one of the key events that occurs during the development of renal tubulointerstitial fibrosis (1-5), contributing to renal fibrogenesis. Previous research has demonstrated that various injury factors (including high blood glucose, proteinuria, hypertension, high blood cholesterol, high protein intake and uremic toxins) can all lead to renal tubular injury, which then aggravates the progression of renal fibrosis (6-9). Recently, dysregulation of lipid metabolism in the occurrence and development of renal interstitial fibrosis, has received increasingly widespread awareness by international kidney disease experts. Oxidized low-density lipoprotein (Ox-LDL), the most widely studied of all lipoproteins, has been reported to cause renal injuries through multiple mechanisms. Ox-LDL, a LDL oxidation product with potent cell cytotoxic properties, is considered an indicator of oxidative stress levels in mesangial cells, which can trigger intracellular lipid oxidation, release of reactive nitrogen 
and reactive oxygen species (ROS), and deteriorative oxidative stress, thus further promoting cell injury (10). However, previous studies have focused on renal intraglomerular mesangial cells, endothelial cells and monocyte/macrophage cells, and explored the roles of Ox-LDL in promoting glomerular injuries and sclerosis (10-12). Few research results have been reported on the injury effects and mechanisms of Ox-LDL in human renal proximal tubular epithelial cells and on whether antioxidant therapy could alleviate the injury.

Lectin-like oxidized low-density lipoprotein receptor-1 (LOX-1), a receptor of Ox-LDL that was first discovered and identified in bovine aortic endothelial cells (13), is expressed in endothelial cells, macrophages, vascular smooth muscle cells, platelets, and adipocytes, but also in epithelial cells $(14,15)$. As LOX-1 can bind to multiple ligands, it has diverse physiological functions and critical roles in signal transduction.

Oxidative stress, a major cause of cell damage, aging and cell death, has recently received increasing attention regarding its role in renal tubule injury. Kidney tissues require a higher oxygen consumption to complete the active transport and reabsorption of water and electrolytes. Therefore, renal tubules are more susceptible to oxidative damage. As a second messenger in a variety of signaling pathways, ROS participates in numerous physiological and pathological processes, including proliferation, differentiation and apoptosis (16-19). It is generally accepted that damage of ROS to the kidney is normally in the deposition of glomerular extracellular matrix (ECM) and renal tubular EMT (20-22). Probucol, as an antioxidant and anti-inflammatory drug, reduces ROS production. It has been reported that probucol could ameliorate renal tubular EMT in a diabetic nephropathy rat model (23).

Previous studies have suggested that the dysregulation of lipid metabolism may also be involved in the renal tubular transdifferentiation process, and ultimately may lead to the occurrence of renal interstitial fibrosis (24). However, there is little evidence supporting this hypothesis and the mechanism remains unclear. For that purpose, the present study examined the EMT status and the LOX-1 and ROS production in cultured renal proximal tubular cells induced with Ox-LDL. In addition, the molecular mechanism and downstream signaling pathways of LOX-1 and ROS were investigated, as well as the potential protective effects of the antioxidant reagent probucol on the above processes.

\section{Materials and methods}

Cell culture. Human HK-2 renal proximal tubule epithelial cells (American Type Culture Collection, Manassas, VA, USA) were cultured in Dulbecco's modified Eagle's medium (DMEM)-F12 medium (Thermo Fisher Scientific, Inc., Waltham, MA, USA) supplemented with $10 \%$ fetal bovine serum (Biochrom, Ltd., Cambridge, UK), L-glutamine $(2 \mathrm{mM})$, penicillin $(100 \mathrm{U} / \mathrm{ml})$, and streptomycin $(100 \mu \mathrm{g} / \mathrm{ml})$ (all from Thermo Fisher Scientific, Inc.) in a humidified incubator containing $5 \% \mathrm{CO}_{2}$ at $37^{\circ} \mathrm{C}$. Cells were pretreated with $20 \mu \mathrm{mol} / 1$ probucol or $250 \mu \mathrm{g} / \mathrm{ml}$ LOX-1 inhibitor polyinosinic acid (both from Sigma-Aldrich; Merck KGaA, Darmstadt, Germany) for $2 \mathrm{~h}$ in advance, and stimulated with Ox-LDL (0-100 $\mu \mathrm{g} / \mathrm{ml}$; Peking Union-Biology Co., Ltd., Beijing, China) for $24 \mathrm{~h}$.
MTT assay. Cells plated in 96-well plates $\left(2 \times 10^{4} /\right.$ well) in $200 \mu \mathrm{l}$ medium were treated with $50 \mu \mathrm{g} / \mathrm{ml} \mathrm{Ox-LDL}$ for $0-72 \mathrm{~h}$ or 0-200 $\mu \mathrm{g} / \mathrm{ml}$ Ox-LDL for $24 \mathrm{~h}$. Cells were incubated with $20 \mu 15 \mathrm{~g} / \mathrm{l}$ MTT solution (Sigma-Aldrich; Merck KGaA) for $4 \mathrm{~h}$. The supernatant was then removed, and $100 \mu 1$ of DMSO was added to each well. The absorbance at $570 \mathrm{~nm}$ was measured using a spectrophotometric plate reader (Bio-Rad Laboratories, Inc., Hercules, CA, USA). Results were quantified from four independent experiments.

Nitric oxide (NO) measurement. NO was determined using the Total NO assay kit (Beyotime Institute of Biotechnology, Shanghai, China). HK-2 cells were seeded in 96-well culture plates $\left(8 \times 10^{4}\right.$ cells/well), pretreated with $20 \mu \mathrm{mol} / 1$ probucol or $250 \mu \mathrm{g} / \mathrm{ml} \mathrm{LOX}-1$ inhibitor polyinosinic acid as mentioned above, and then stimulated with $50 \mu \mathrm{g} / \mathrm{m} 1 \mathrm{Ox}-\mathrm{LDL}$ for $24 \mathrm{~h}$ at $37^{\circ} \mathrm{C}$. Then, the culture supernatants were used to determine the concentration of NO. The standard provided in the kit was diluted with DMEM-F12 medium to a variety of concentrations, as indicated: $0,1,2,5,10,20,40,60$ and $100 \mu \mathrm{g} / \mathrm{ml}$. Afterwards, the supernatant of each sample or $50 \mu \mathrm{l}$ of the above standard were added in a 96-well plate together with $50 \mu \mathrm{l}$ Griess Reagent I and Griess Reagent II. The absorbance at $550 \mathrm{~nm}$ was measured using a spectrophotometric plate reader (Bio-Rad Laboratories, Inc.). Results were quantified from four independent experiments.

Intracellular ROS measurement. The intracellular ROS levels were measured using the specific probe 2',7'-dichlorodihydrofluorescein diacetate (DCFH-DA; Beyotime Institute of Biotechnology) kit. HK-2 cells seeded $\left(8 \times 10^{5}\right.$ cells/well) in 6-well cell culture plates were pretreated by probucol or polyinosinic acid as mentioned above, and then stimulated with $50 \mu \mathrm{g} / \mathrm{m} 1 \mathrm{Ox}$-LDL for $24 \mathrm{~h}$ at $37^{\circ} \mathrm{C}$. Afterwards, serum-free medium containing $10 \mu \mathrm{M}$ DCFH-DA was added to each well for $20 \mathrm{~min}$ at $37^{\circ} \mathrm{C}$ in the dark. In order to fully remove the remaining DCFH-DA, the cells were washed with serum-free medium three times, then detached from the plates with $0.25 \%$ trypsin, and collected by centrifugation at $300 \mathrm{x}$ g for $5 \mathrm{~min}$ at $4^{\circ} \mathrm{C}$. Positive control cells were simultaneously treated with Rosup (a ROS positive control provided by the kit). FACScan flow cytometric and CellQuest Pro software v5.1 (both from BD Biosciences, San Jose, CA, USA) analyses were conducted on the various cell treatment groups to detect the average fluorescence intensity of dichlorofluorescein (DCF), at an excitation wavelength of $488 \mathrm{~nm}$ and at an emission wavelength of $525 \mathrm{~nm}$. Results were quantified from four independent experiments.

Western blotting. Proteins were extracted using a radioimmunoprecipitation lysis buffer (Beyotime Institute of Biotechnology) that contains the protease inhibitor cocktail (Sigma-Aldrich; Merck KGaA) and protein concentrations were calculated by using the Pierce bicinchoninic protein assay kit (Thermo Fisher Scientific, Inc.). An equal amount of protein $(40 \mu \mathrm{g})$ was taken from each group. The samples were mixed with 5X SDS sample buffer and heated at $100^{\circ} \mathrm{C}$ for $5 \mathrm{~min}$, then loaded onto 10 or $12 \%$ Tris-glycine SDS-PAGE gel and separated at $100 \mathrm{~V}$ for 1.5 to $2 \mathrm{~h}$. Primary antibodies against E-cadherin (cat no. 14472; 1:1,000), extracellular signal-regulated kinase (ERK; 
cat no. 4696; 1:2,000), phosphorylated (p-) ERK (cat no. 4094; 1:1,000), p38 (cat no. 9218; 1:1,000) and p-p38 (cat no. 9216; 1:2,000) were purchased from Cell Signaling Technology, Inc. (Danvers, MA, USA). Primary antibodies against LOX-1 (cat no. sc-20753; 1:300), NADPH oxidase 4 (NOX4; cat no. sc-30141; 1:300), and p22phox (cat no. sc-271968; 1:200) were purchased from Santa Cruz Biotechnology, Inc. (Dallas, TX, USA). Primary antibodies against $\alpha$-SMA (cat no. A2547; $1: 500$ ) and $\beta$-actin (cat no. A5441; 1:1,000) were purchased from Sigma-Aldrich (Merck KGaA). Following transferring of proteins to a polyvinylidene fluoride membrane, nonspecific binding to the membrane was blocked with 5\% non-fat dry milk for $2 \mathrm{~h}$ at room temperature. The membranes were then incubated overnight at $4{ }^{\circ} \mathrm{C}$ with primary antibodies against LOX-1, $\alpha$-SMA, E-cadherin, NOX4, p22phox, ERK, p-ERK, ERK, p-p38, and p38. Following washing, membranes were incubated with goat anti-mouse (cat no. BA1051; 1:2,000) or anti-rabbit (cat no. BA1055; 1:2,000) (both from Wuhan Boster Biological Technology, Ltd., Wuhan, China) horseradish peroxidase-conjugated secondary antibodies for $1 \mathrm{~h}$ at room temperature. The signals were visualized by enhanced chemiluminescence (Pierce; Thermo Fisher Scientific, Inc.). ImageJ 1.37 (National Institute of health, Bethesda, MD, USA) analysis system was used to analyze the signal absorbance.

Statistical analysis. Statistical analyses were performed using SPSS software (version 21.0; IBM SPSS, Armonk, NY, USA). All the data represent at least three independent experiments and are expressed as the means \pm standard deviation unless otherwise indicated. Differences between groups were determined using an unpaired Student's t-test or a one-way analysis of variance (anova; S-N-K post hoc test was used after the anova) when multiple comparisons were required. $\mathrm{P}<0.05$ was considered to indicate a statistically significant difference.

\section{Results}

Effect of $O x-L D L$ on the viability of $H K-2$ cells. The effect of Ox-LDL stimulation on the viability of HK-2 cells was examined using the MTT assay. The results demonstrated that there was a slight decrease in the total numbers of viable cells in the Ox-LDL-stimulated groups in different times (24-72 h) but over the range of different dosages $(12.5-200 \mu \mathrm{g} / \mathrm{ml})$ after $24 \mathrm{~h}$ there was only a small change in cell viability, compared with the control untreated group (Fig. 1). However, the differences were not significant $(\mathrm{P}>0.05)$, suggesting that $\mathrm{Ox}-\mathrm{LDL}$ had no effect on the viability of HK-2 cells at the doses and times tested.

Effect of $O x-L D L$ on $\alpha$-SMA, E-cadherin and LOX-1 protein expression in $H K-2$ cells. To investigate the effects of Ox-LDL stimulation on EMT in HK-2cells, the protein expression levels of the mesenchymal marker $\alpha$-SMA and of the epithelial marker E-cadherin, as well as LOX-1 expression, were determined by western blotting. The results demonstrated that stimulation with Ox-LDL $(25-100 \mu \mathrm{g} / \mathrm{ml})$ resulted in a significant increase in the expression of LOX-1 and $\alpha$-SMA in HK-2 cells in a dose-dependent manner, while E-cadherin expression was significantly decreased (Fig. 2).
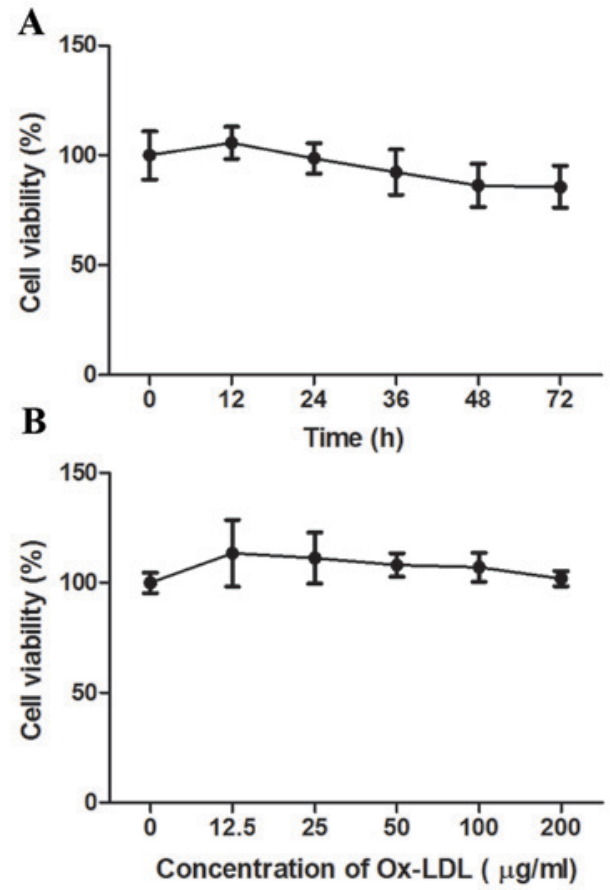

Figure 1. Effect of Ox-LDL on the viability of HK-2 cells. HK-2 cells were induced with (A) $50 \mu \mathrm{g} / \mathrm{ml}$ Ox-LDL for different times $(0,12,24,36,48$ and $72 \mathrm{~h}$ ) or (B) different dosages of Ox-LDL $(0-200 \mu \mathrm{g} / \mathrm{ml})$ for $24 \mathrm{~h}$, and then cell viability was measured by MTT assay. Four samples were used for each group, and the experiments were repeated four independent times. Data are presented as the means \pm standard deviation. Ox-LDL, oxidized low density lipoprotein

Effect of probucol on $\alpha$-SMA, E-cadherin, and LOX-1 protein expression in $O x-L D L-$ stimulated $H K-2$ cells. According to the above results, the dose of $50 \mu \mathrm{g} / \mathrm{ml} \mathrm{Ox}-\mathrm{LDL}$ was selected to stimulate HK-2 cells in the following experiments. Cells were pretreated with probucol $(20 \mu \mathrm{mol} / \mathrm{l})$ or the LOX-1 inhibitor polyinosinic acid $(250 \mu \mathrm{g} / \mathrm{ml})$, stimulated with Ox-LDL and then analyzed by western blotting. The results demonstrated a significant increase in $\alpha$-SMA and LOX-1 protein expression levels in HK-2 cells stimulated with $50 \mu \mathrm{g} / \mathrm{ml}$ Ox-LDL, and this effect was significantly inhibited by probucol or polyinosinic acid pretreatment (Fig. 3). Of note, the inhibition of LOX-1 expression by probucol was weaker than by polyinosinic acid (Fig. 3). E-cadherin protein expression levels exhibited the opposite effect, with decreasing levels following Ox-LDL stimulation and increasing levels following probucol or polyinosinic acid pretreatment (Fig. 3).

Effects of probucol on ROS and NO production in $O x$-LDL-stimulated $H K-2$ cells. To specify whether oxidative stress was involved in the process of EMT in HK-2 cells induced by Ox-LDL, the production of ROS was examined using the specific probe DCFH-DA and the concentration of $\mathrm{NO}$ was detected using a biochemical colorimetric method. The results revealed that the basic activity of ROS in HK-2 cells was $451.5 \mu \mathrm{g} / \mathrm{ml}$. Following stimulation with $50 \mu \mathrm{g} / \mathrm{ml}$ Ox-LDL, ROS activity increased to $839.8 \mu \mathrm{g} / \mathrm{ml}(\mathrm{P}<0.05$; Fig. 4A), however, this increase was inhibited by probucol or polyinosinic acid pretreatment $(\mathrm{P}<0.05$; Fig. $4 \mathrm{~A})$. The concentration of NO in the culture supernatant of the control unstimulated HK-2 cells was $46.0 \mu \mathrm{mol} / \mathrm{l}$ (Fig. 4B). Following stimulation 

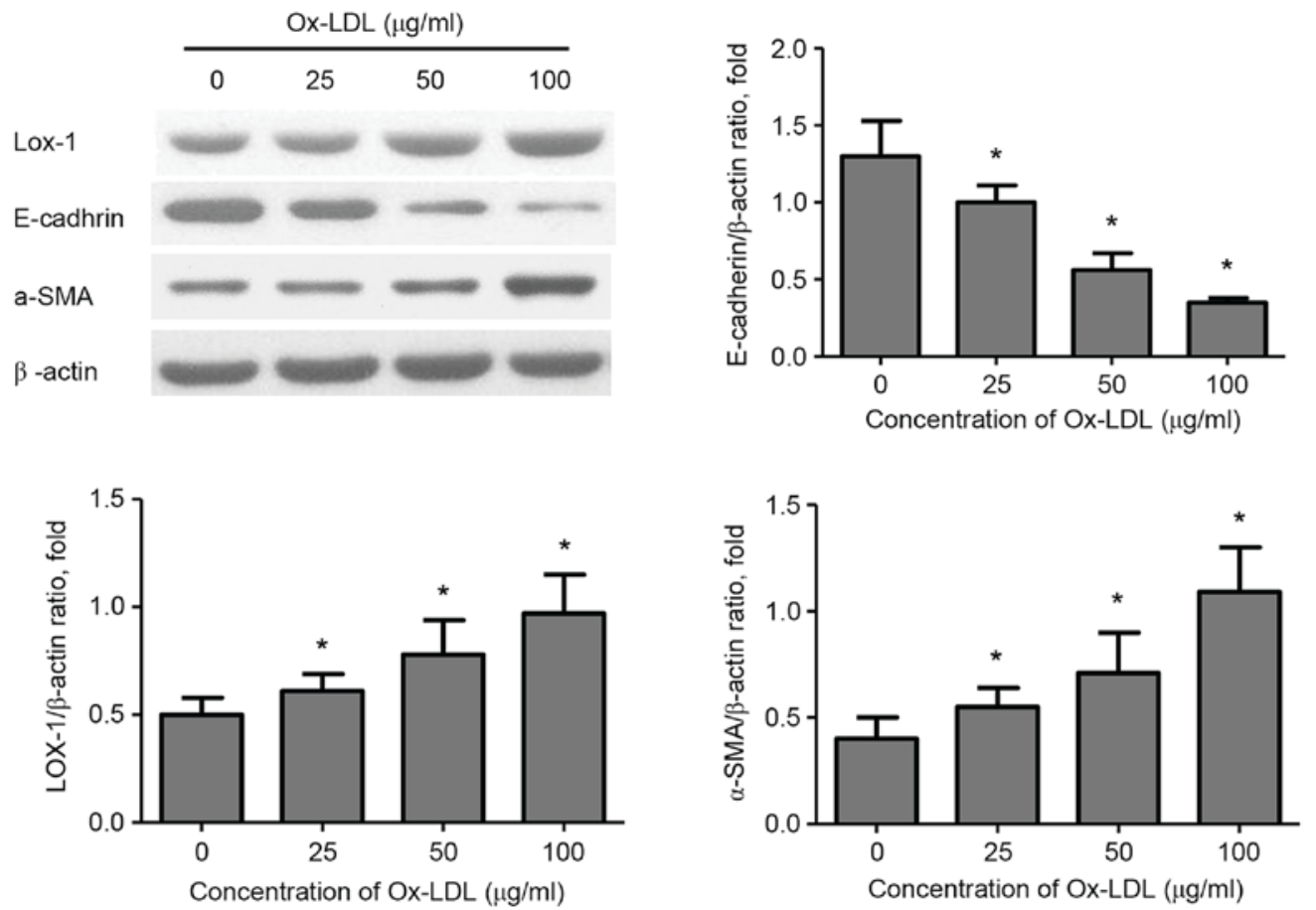

Figure 2. Effect of Ox-LDL on the EMT status of HK-2 cells. Cells were stimulated with Ox-LDL (0-100 $\mu \mathrm{g} / \mathrm{ml})$ for $24 \mathrm{~h}$ and the protein expression levels of LOX-1, E-cadherin and $\alpha$-SMA were analyzed by western blotting. Representative images and quantification, with $\beta$-actin used as a loading control. "P<0.05 vs. control. Ox-LDL, oxidized low density lipoprotein; EMT, epithelial-mesenchymal transition; LOX-1, lectin-like oxidized low-density lipoprotein receptor-1; SMA, smooth muscle actin.
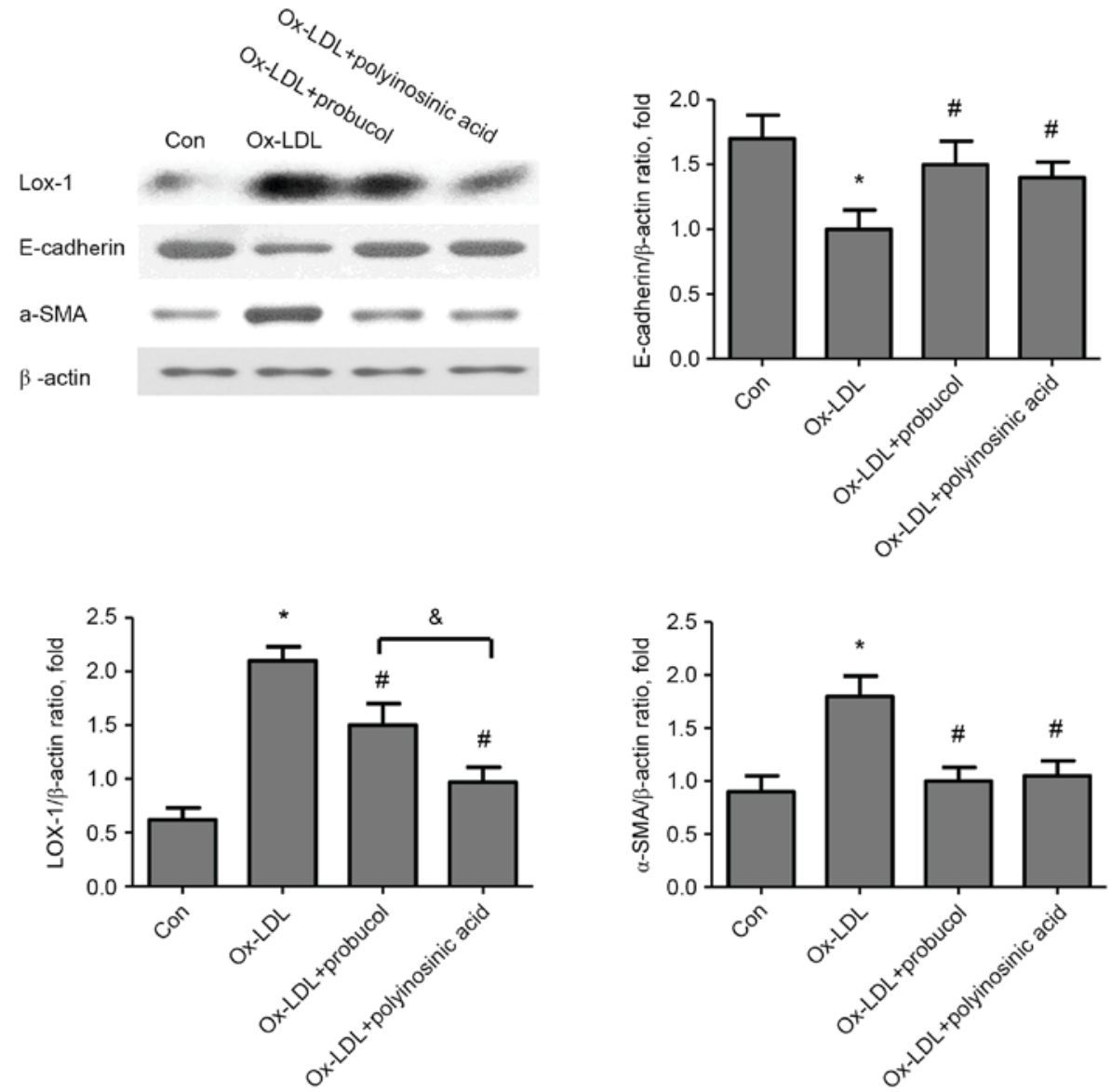

Figure 3. Effect of probucol on Ox-LDL-induced EMT in HK-2 cells. Cells were pretreated with probucol or with the LOX-1 inhibitor polyinosinic acid, stimulated with Ox-LDL for $24 \mathrm{~h}$, and then analyzed by western blotting. Representative images and quantification, with $\beta$-actin used as a loading control. ${ }^{*} \mathrm{P}<0.05$ vs. control; ${ }^{*} \mathrm{P}<0.05$ vs. Ox-LDL alone; and ${ }^{\&} \mathrm{P}<0.05$ as indicated by bracket. Ox-LDL, oxidized low density lipoprotein; EMT, epithelial-mesenchymal transition; LOX-1, lectin-like oxidized low-density lipoprotein receptor-1; SMA, smooth muscle actin; Con, control. 


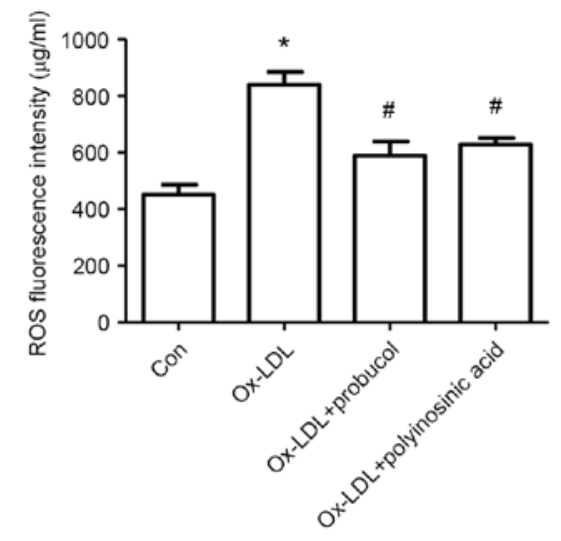

C

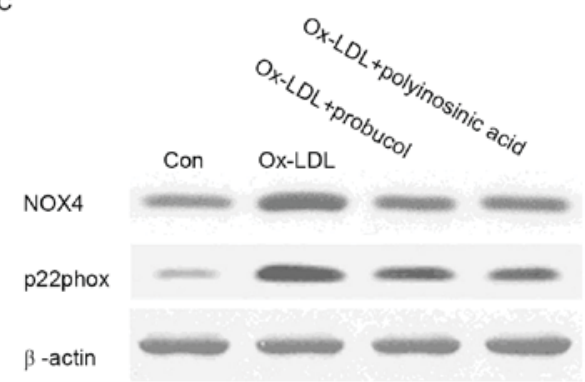

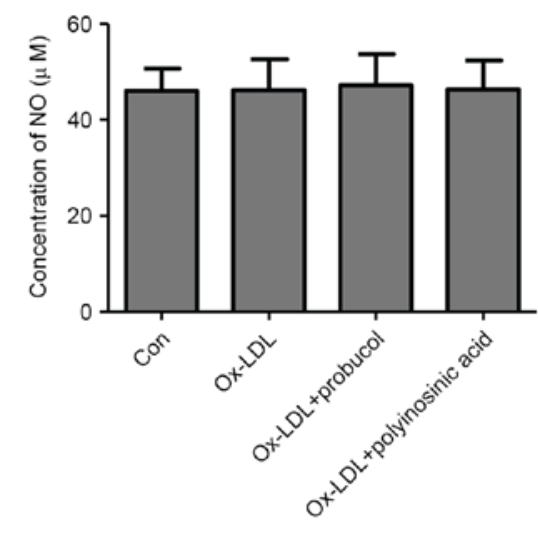

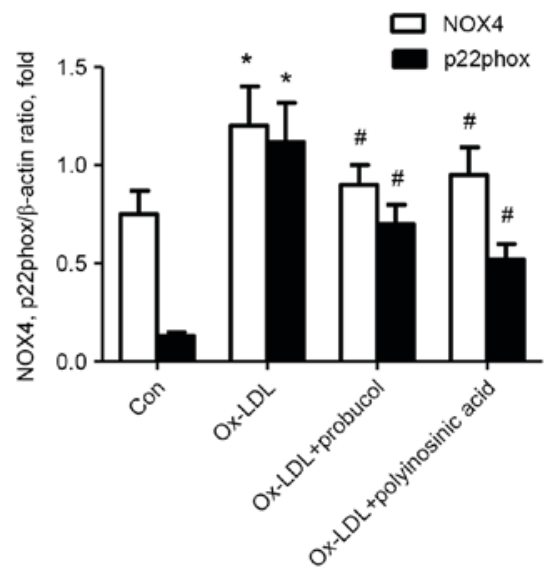

Figure 4. Effect of probucol on Ox-LDL-induced ROS generation and NOX4 and p22phox expression in HK-2 cells. Cells were pretreated with probucol or with the LOX-1 inhibitor polyinosinic acid, and then stimulated with Ox-LDL. (A) ROS production was measured with a specific probe and flow cytometry. (B) NO concentration was measured with a biochemical colorimetric method. (C) Protein expression levels of NOX4 and p22phox were examined by western blot analysis. Representative images and quantification, with $\beta$-actin used as a loading control. " $\mathrm{P}<0.05$ vs. control; and ${ }^{\#} \mathrm{P}<0.05$ vs. Ox-LDL alone. Ox-LDL, oxidized low density lipoprotein; ROS, reactive oxygen species; NOX4, NADPH oxidase 4; p22phox, cytochrome b-245 $\alpha$ chain; LOX-1, lectin-like oxidized low-density lipoprotein receptor-1; NO, nitric oxide; Con, control.

with $50 \mu \mathrm{g} / \mathrm{ml}$ Ox-LDL, NO concentration was $46.2 \mu \mathrm{mol} / 1$, which was not significantly different compared with control (P>0.05; Fig. 4B). Similarly, pretreatment with probucol or polyinosinic acid did not have any effect on $\mathrm{NO}$ concentration (P>0.05; Fig. 4B).

Effects of probucol on NOX4 and p22phox expression in $O x$-LDL-stimulated HK-2 cells. Because NADPH oxidase activation is a major source of ROS in cells, the effect of probucol on the oxidative stress-related proteins NOX4 and p22phox was examined in HK-2 cells induced by Ox-LDL. Western blot analysis demonstrated an obvious increase in the protein expression levels of NOX4 and p22phox following OX- LDL stimulation (Fig. 4C). However, pretreatment with probucol or polyinosinic acid significantly suppressed these increases ( $\mathrm{P}<0.05$; Fig. 4C).

Effect of probucol on ERK1/2 and p38 MAPK signaling pathways in $O x$ - $L D L$-induced $H K-2$ cells. To further understand the mechanism responsible for the Ox-LDL-induced EMT in renal tubular epithelial cells, the activation status of the ERK1/2 and p38 MAPK signaling pathways was investigated. Following Ox-LDL stimulation in HK-2 cells, an increase in both ERK1/2 and p38 phosphorylation was observed at 5 min of stimulation, and peaking at $30 \mathrm{~min}$ (Fig. 5A). ERK1/2 and p38 phosphorylation was significantly inhibited by pretreatment with probucol or polyinosinic acid (Fig. 5B).

\section{Discussion}

Renal fibrosis, characterized by glomerulosclerosis and tubulointerstitial fibrosis, is the final common pathway of a wide variety of chronic kidney disease (CKD) leading to the complete destruction of kidney parenchyma and end-stage renal disease, requiring dialysis or kidney transplant (25). Studies have demonstrated that in renal fibrosis, the correlation of renal tubulointerstitial fibrosis with renal function is much closer than of glomerulosclerosis (26). The renal proximal tubular epithelial cells, which are susceptible to injuries by a wide variety of factors, are generally considered to have a pivotal role in fibrogenesis. The proximal tubular epithelial cells undergo EMT, resulting in matrix-producing fibroblasts, and thereby contributing to the pathogenesis of renal interstitial fibrosis and end-stage renal failure.

In the present study, the lipoprotein Ox-LDL was demonstrated to induce EMT in tubular epithelial cells. A small amount of LOX-1 expression was observed in control HK-2 cells, which was then upregulated by Ox-LDL stimulation in 
A
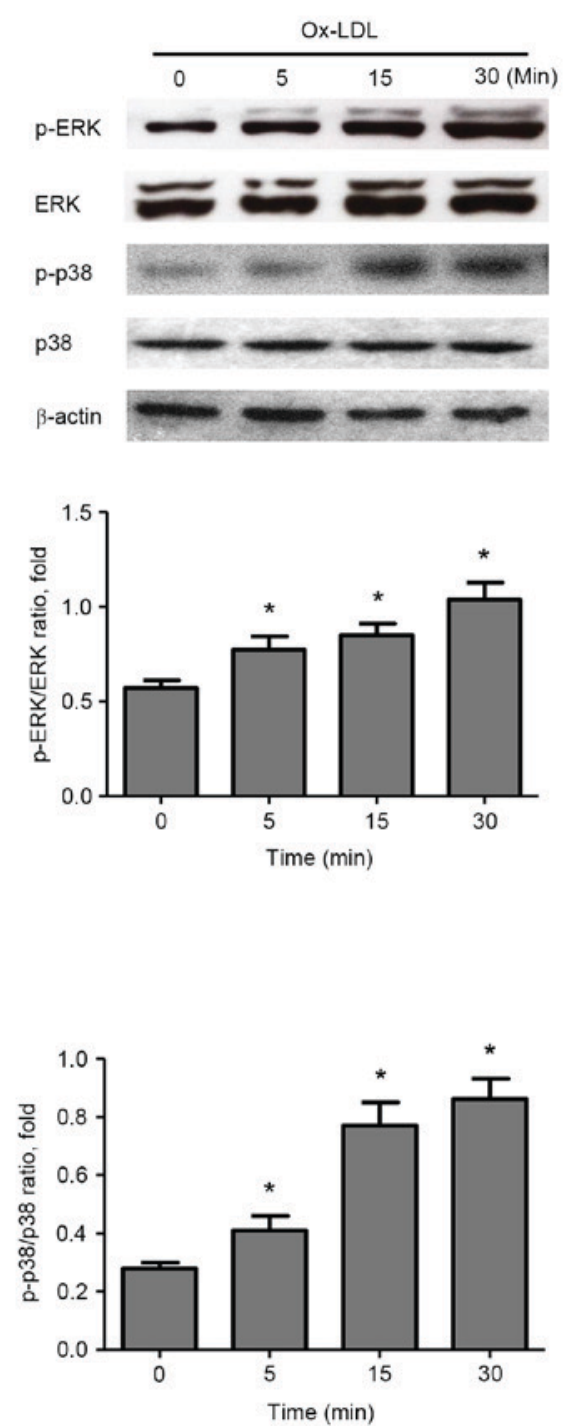

B
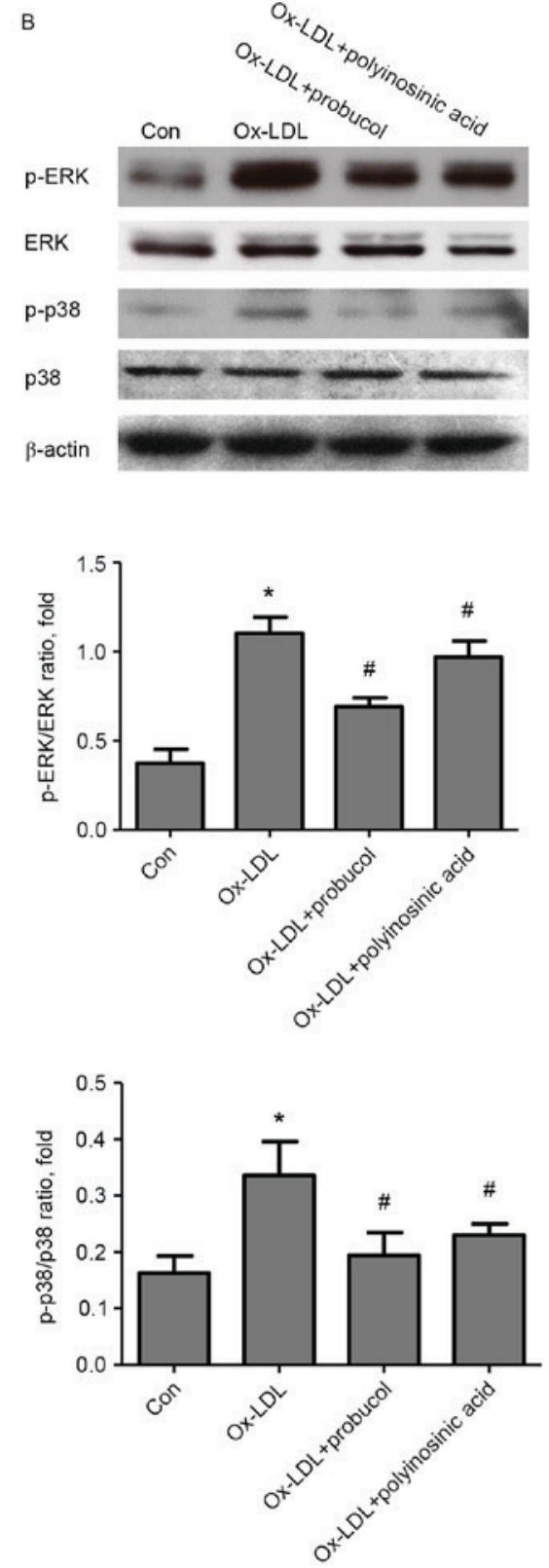

Figure 5. Effect of probucol on ERK and p38 MAPK signaling in Ox-LDL-induced HK-2 cells. (A) Cells were stimulated with Ox-LDL (50 $\mu \mathrm{g} / \mathrm{ml}$ ) for 5, 15 and $30 \mathrm{~min}$ and then analyzed by western blotting, in order to determine the effect of Ox-LDL on ERK and p38 MAPK pathway activation. (B) Cells were pretreated with probucol $(20 \mu \mathrm{mol} / \mathrm{l})$ or with the LOX-1 inhibitor polyinosinic acid $(250 \mu \mathrm{g} / \mathrm{ml})$ for $2 \mathrm{~h}$, stimulated with Ox-LDL $(50 \mu \mathrm{g} / \mathrm{ml})$ for $30 \mathrm{~min}$, and then analyzed by western blotting. Representative images and quantification, with $\beta$-actin used as a loading control. ${ }^{*} \mathrm{P}<0.05$ vs. control; and ${ }^{\#} \mathrm{P}<0.05$ vs. Ox-LDL alone. ERK, extracellular signal-regulated kinase; MAPK, mitogen-activated protein kinase; Ox-LDL, oxidized low density lipoprotein; LOX-1, lectin-like oxidized low-density lipoprotein receptor-1; p, phosphorylated; Con, control.

a dose-dependent manner, indicating that LOX-1 may have contributed to the EMT of proximal tubular epithelial cells. In order to determine the mechanism of LOX-1 in the injury of HK-2 cells, the LOX-1 inhibitor polyinosinic acid and the antioxidant probucol were used to pretreat the cells. The results indicated that pretreatment suppressed both LOX-1 expression and EMT. In addition, Ox-LDL was demonstrated to induce oxidative stress, with expression of p22phox and NOX4 and production of ROS significantly increased in HK-2 cells following Ox-LDL stimulation. However, these increases were inhibited by pretreatment with the LOX-1 inhibitor or probucol. No significant differences were observed in NO concentration in any of the treatment groups. Of note, the inhibition of
LOX-1 by probucol was weaker than by the LOX-1 inhibitor, suggesting that Ox-LDL induced LOX-1 expression, which may have activated NADPH oxidase-mediated ROS generation and LOX-1 upregulation. These observations provide evidence for a positive feedback loop involving Ox-LDL, NADPH oxidase-mediated ROS generation and LOX-1.

Recently, there has been increasing interest in the role of LOX-1 in the progression of renal diseases. A previous study has reported that high glucose levels can induce the expression of LOX-1 at the gene promoter/transcription level via a p38 MAPK-dependent mechanism, leading to Ox-LDL-induced apoptosis in renal tubular epithelial cells (27). It has also been reported that LOX-1 and NADPH oxidase are upregulated in 
human renal proximal tubular epithelial cells induced with angiotensin II (Ang II), and that the activation of the MAPK pathway occurs downstream of the Ang II/ROS/LOX-1 cascade (28). A study in LDLr-null mice has demonstrated that high fat diet induced renal fibrosis through activation of the LOX-1/p38, p44/42/nuclear factor $-\kappa B$ pathway by Ox-LDL (29). The above studies suggest that an increase in LOX-1 expression is observed in renal tubular epithelial cells, and this is associated with the pathogenesis and progression of chronic renal tubular and interstitial diseases. The present results demonstrated that LOX-1 expression was increased following Ox-LDL stimulation and EMT induction in HK-2 cells, which is consistent with previous studies.

Renal tubules are known to be susceptible to injury from oxidative stress, in which ROS are crucial cell-damaging molecules. Studies reveal that ROS induces apoptosis and EMT in renal tubular epithelial cells through the MAPK pathway $(20,30,31)$. High glucose induces EMT by decreasing intracellular ROS levels via the downregulation of NADPH oxidase subunits NOX1 and NOX4, and activation of ERK1/2 is associated with high glucose-induced EMT in HK-2 cells (21). The present results demonstrated that Ox-LDL stimulation triggered oxidative stress and NOX4 and p22phox upregulation, but NO was not involved in this process.

The MAPK pathway, which includes ERK, c-Jun N-terminal kinase (JNK) and p38 MAPKs (32-34), can be activated by ROS. Previous studies have demonstrated that ERK and p38 MAPK signaling pathways have a vital role in EMT, inflammation of renal proximal tubule epithelial cells and renal injury (33,35-39). Zhou et al (38) reported that the knockdown of thioredoxin-interacting protein antagonized the high glucose-induced EMT by inhibiting ROS production and by activation of p38 MAPK and ERK1/2 (40). ROS is also important in transforming growth factor- $\beta 1$-induced EMT, primarily through activation of p38, ERK MAPKs, and the subsequent ERK-directed activation of the Smad pathway in proximal tubular epithelial cells (20). Consistent with previous studies, probucol and polyinosinic acid pretreatments were demonstrated to prevent the Ox-LDL-mediated activation of ERK and p38 MAPKs in HK-2 cells, indicating that probucol may protect HK-2 cells against Ox-LDL-induced EMT by modulating the ERK and p38 MAPK signaling pathways.

Probucol is a phenolic lipid-lowering prototype agent with anti-inflammatory and antioxidant properties, and has a long history of clinical application for the treatment and prevention of cardiovascular diseases. Its ability to consume oxidation substances, such as oxygen free radicals, serves an important role in its antioxidant, anti-inflammatory and antiapoptotic functions. In a rat model of diabetic nephropathy, probucol inhibited EMT in renal tubular epithelial cells by downregulating specificity protein 1 expression in kidney (23). It has also been reported to attenuate podocytes injury in type 2 diabetic nephropathy of $\mathrm{db} / \mathrm{db}$ mice through the suppression of NADPH oxidase NOX2 (41). The present data revealed that probucol may have a protective role on the injury of HK-2 cells by modulating LOX-1 and oxidative stress.

There is controversy regarding the use of probucol in cardiovascular diseases and some western countries have stopped its use because of the reduction in serum
HDL-cholesterol (HDL-C). However the HDL-C reduction may not be a 'side effect' but may reflect a mechanism of action of probucol as it causes a decrease in HDL-C by enhancing plasma cholesteryl ester transfer protein activity and hepatic scavenger receptor class B type I. Probucol also accelerates the antioxidant function of HDL via increasing paraoxonase 1 activity (42). In particular, a significant coronary artery disease risk reduction has been demonstrated in the long-term treatment of patients with heterozygous familial hypercholesterolemia (FH) in Japan with probucol (43). And there is also evidence for the pleiotropic and beneficial therapeutic effects of probucol on the cardiovascular system and in chronic kidney disease $(42,44)$. As a result of these studies it is clear that probucol may have beneficial therapeutic effects in certain suitable CKD patients. In conclusion, probucol may postpone renal interstitial fibrosis through the suppression of Ox-LDL-induced EMT in HK-2 cells via the downregulation of LOX-1, NADPH oxidase, and ROS production and the inhibition of MAPK signaling activation. The present findings suggest that probucol may serve as a useful antioxidant agent for postponing the progression of renal interstitial diseases. However, further in vivo and in vitro studies are needed to elucidate the mechanism involved.

\section{Acknowledgements}

This study was supported by funding from the National Natural Science Foundation of China (grant no. 81473480), Key Medical Discipline Project Shanghai Municipal Health Bureau (grant no. ZK2015A18), Independent Innovation Research Fund of Putuo District Science and Technology Committee (grant no. 2012PTKW006), Potential Health Professionals in Shanghai University of Traditional Chinese Medicine (grant no. B-X-78), and Shanghai Municipal Health and Family Planning Commission (grant no. 201540056).

\section{References}

1. Galichon P and Hertig A: Epithelial to mesenchymal transition as a biomarker in renal fibrosis: Are we ready for the bedside? Fibrogenesis Tissue Repair 4: 11, 2011.

2. He J, Xu Y, Koya D and Kanasaki K: Role of the endothelial-to-mesenchymal transition in renal fibrosis of chronic kidney disease. Clin Exp Nephrol 17: 488-497, 2013.

3. Carew RM, Wang B and Kantharidis P: The role of EMT in renal fibrosis. Cell Tissue Res 347: 103-116, 2012.

4. Liu Y: Renal fibrosis: New insights into the pathogenesis and therapeutics. Kidney Int 69: 213-217, 2006.

5. Allison SJ: Fibrosis: Targeting EMT to reverse renal fibrosis. Nat Rev Nephrol 11: 565, 2015.

6. Zha D, Cheng H, Li W, Wu Y, Li X, Zhang L, Feng YH and Wu X: High glucose instigates tubulointerstitial injury by stimulating hetero-dimerization of adiponectin and angiotensin II receptors. Biochem Biophys Res Commun: pii: S0006-291X(17)31600-5, 2017.

7. Wahl P, Ducasa GM and Fornoni A: Systemic and renal lipids in kidney disease development and progression. Am J Physiol Renal Physiol 310: F433-F445, 2016.

8. Cuenca-Sánchez M, Navas-Carrillo D and Orenes-Piñero E: Controversies surrounding high-protein diet intake: Satiating effect and kidney and bone health. Adv Nutr 6: 260-266, 2015.

9. Noone D and Licht C: Chronic kidney disease: A new look at pathogenetic mechanisms and treatment options. Pediatr Nephrol 29: 779-792, 2014.

10. Lee HS and Song CY: Oxidized low-density lipoprotein and oxidative stress in the development of glomerulosclerosis. Am J Nephrol 29: 62-70, 2009. 
11. Lee HS, Kim BC, Kim YS, Choi KH and Chung HK: Involvement of oxidation in LDL-induced collagen gene regulation in mesangial cells. Kidney Int 50: 1582-1590, 1996.

12. Romayne Kurukulasuriya L, Athappan G, Saab G, Whaley Connell A and Sowers JR: HMG CoA reductase inhibitors and renoprotection: The weight of the evidence. Ther Ady Cardiovasc Dis 1: 49-59, 2007.

13. Sawamura T, Kume N, Aoyama T, Moriwaki H, Hoshikawa H, Aiba Y, Tanaka T, Miwa S, Katsura Y, Kita T and Masaki T: An endothelial receptor for oxidized low-density lipoprotein. Nature 386: 73-77, 1997.

14. Hu C, Kang BY, Megyesi J, Kaushal GP, Safirstein RL and Mehta JL: Deletion of LOX-1 attenuates renal injury following angiotensin II infusion. Kidney Int 76: 521-527, 2009.

15. Kelly KJ, Wu P, Patterson CE, Temm C and Dominguez JH: LOX-1 and inflammation: A new mechanism for renal injury in obesity and diabetes. Am J Physiol Renal Physiol 294: F1136-F1145, 2008

16. Yang L, Wu L, Du S, Hu Y, Fan Y and Ma J: 1,25(OH)2D3 inhibits high glucose-induced apoptosis and ROS production in human peritoneal mesothelial cells via the MAPK/P38 pathway. Mol Med Rep 14: 839-844, 2016.

17. Pinto M, Pickrell AM, Wang X, Bacman SR, Yu A, Hida A, Dillon LM, Morton PD, Malek TR, Williams SL and Moraes CT: Transient mitochondrial DNA double strand breaks in mice cause accelerated aging phenotypes in a ROS-dependent but p53/p21-independent manner. Cell Death Differ 24: 288-299, 2017.

18. Lan X, Lederman R, Eng JM, Shoshtari SS, Saleem MA, Malhotra A and Singhal PC: Nicotine induces podocyte apoptosis through increasing oxidative stress. PLoS One 11: e0167071, 2016.

19. Guo Y,Han B, Luo K, Ren Z, Cai L and Sun L: NOX2-ROS-HIF-1a signaling is critical for the inhibitory effect of oleanolic acid on rectal cancer cell proliferation. Biomed Pharmacother 85 733-739, 2017.

20. Rhyu DY, Yang Y,Ha H, Lee GT, Song JS, Uh ST and Lee HB: Role of reactive oxygen species in TGF-beta1-induced mitogen-activated protein kinase activation and epithelial-mesenchymal transition in renal tubular epithelial cells. J Am Soc Nephrol 16 667-675, 2005

21. He T, Guan X, Wang S, Xiao T, Yang K, Xu X, Wang J and Zhao J: Resveratrol prevents high glucose-induced epithelial-mesenchymal transition in renal tubular epithelial cells by inhibiting NADPH oxidase/ROS/ERK pathway. Mol Cell Endocrinol 402: 13-20, 2015.

22. Jha JC, Thallas-Bonke V, Banal C, Gray SP, Chow BS, Ramm G, Quaggin SE, Cooper ME, Schmidt HH and Jandeleit-Dahm KA: Podocyte-specific Nox4 deletion affords renoprotection in a mouse model of diabetic nephropathy. Diabetologia 59: 379-389, 2016.

23. Duan SB, Liu GL, Wang YH and Zhang JJ: Epithelial-to-mesenchymal transdifferentiation of renal tubular epithelial cell mediated by oxidative stress and intervention effect of probucol in diabetic nephropathy rats. Ren Fail 34: 1244-1251, 2012

24. Ni J, Ma KL, Wang CX, Liu J, Zhang Y, Lv LL, Ni HF, Chen YX, Ruan XZ and Liu BC: Activation of renin-angiotensin system is involved in dyslipidemia-mediated renal injuries in apolipoprotein E knockout mice and HK-2 cells. Lipids Health Dis 12: 49, 2013.

25. Eddy AA: Progression in chronic kidney disease. Adv Chronic Kidney Dis 12: 353-365, 2005.

26. Klahr S, Morrissey J, Hruska K, Wang S and Chen Q: New approaches to delay the progression of chronic renal failure. Kidney Int Suppl: S23-S26, 2002.

27. Zhou X, Liu R, Duan S, Huang G, Ye Y and Kong Y: High glucose enhances oxLDL-induced apoptosis in human renal proximal tubular epithelial cells largely via inducing lectin-like ox-LDL receptor-1. Pharmacology 98: 20-28, 2016.
28. Xu Y, Ruan S, Xie H and Lin J: Role of LOX-1 in Ang II-induced oxidative functional damage in renal tubular epithelial cells. Int J Mol Med 26: 679-690, 2010

29. Dai Y, Palade P, Wang X, Mercanti F, Ding Z, Dai D and Mehta JL: High fat diet causes renal fibrosis in LDLr-null mice through MAPK-NF- $\kappa$ B pathway mediated by Ox-LDL. J Cardiovasc Pharmacol 63: 158-166, 2014.

30. Chang CY, Shen CY, Kang CK, Sher YP, Sheu WH, Chang CC and Lee TH: Taurine protects HK-2 cells from oxidized LDL-induced cytotoxicity via the ROS-mediated mitochondrial and p53-related apoptotic pathways. Toxicol Appl Pharmacol 279: 351-363, 2014.

31. Liu M, Park J, Wu X, Li Y, Tran Q, Mun K, Lee Y, Hur GM, Wen A and Park J: Shen-Kang protects 5/6 nephrectomized rats against renal injury by reducing oxidative stress through the MAPK signaling pathways. Int J Mol Med 36: 975-984, 2015.

32. Wankun X, Wenzhen Y, Min Z, Weiyan Z, Huan C, Wei D, Lvzhen $\mathrm{H}, \mathrm{Xu} \mathrm{Y}$ and Xiaoxin L: Protective effect of paeoniflorin against oxidative stress in human retinal pigment epithelium in vitro. Mol Vis 17: 3512-3522, 2011.

33. Cao Y, Zhang Y, Wang N and He L: Antioxidant effect of imperatorin from Angelica dahurica in hypertension via inhibiting NADPH oxidase activation and MAPK pathway. J Am Soc Hypertens 8: 527-536, 2014

34. Li ZJ, Li XM, Piao YJ, Choi DK, Kim SJ, Kim JW, Sohn KC, Kim CD and Lee JH: Genkwadaphnin induces reactive oxygen species (ROS)-mediated apoptosis of squamous cell carcinoma (SCC) cells. Biochem Biophys Res Commun 450: 1115-1119, 2014.

35. Huang C, Day ML, Poronnik P, Pollock CA and Chen XM: Inhibition of KCa3.1 suppresses TGF-b1 induced MCP-1 expression in human proximal tubular cells through Smad3, p38 and ERK1/2 signaling pathways. Int J Biochem Cell Biol 47: 1-10, 2014.

36. Zhang X, Liang D, Chi ZH, Chu Q, Zhao C, Ma RZ, Zhao Y and $\mathrm{Li} \mathrm{H}$ : Effect of zinc on high glucose-induced epithelial-to-mesenchymal transition in renal tubular epithelial cells. Int J Mol Med 35: 1747-1754, 2015.

37. Bai YH, Wang JP, Yang M,Zeng Y and Jiang HY: SiRNA-HMGA2 weakened AGEs-induced epithelial-to-mesenchymal transition in tubular epithelial cells. Biochem Biophys Res Commun 457: 730-735, 2015.

38. Zhou L, Xue H, Wang Z, Ni J, Yao T, Huang Y, Yu C and Lu L: Angiotensin-(1-7) attenuates high glucose-induced proximal tubular epithelial-to-mesenchymal transition via inhibiting ERK1/2 and p38 phosphorylation. Life Sci 90: 454-462, 2012.

39. Wen Q, Huang Z, Zhou SF, Li XY, Luo N and Yu XQ: Urinary proteins from patients with nephrotic syndrome alters the signalling proteins regulating epithelial-mesenchymal transition. Nephrology (Carlton) 15: 63-74, 2010.

40. Wei J, Shi Y, Hou Y, Ren Y, Du C, Zhang L, Li Y and Duan H: Knockdown of thioredoxin-interacting protein ameliorates high glucose-induced epithelial to mesenchymal transition in renal tubular epithelial cells. Cell Signal 25: 2788-2796, 2013.

41. Zhou G, Wang Y, He P and Li D: Probucol inhibited Nox2 expression and attenuated podocyte injury in type 2 diabetic nephropathy of db/db mice. Biol Pharm Bull 36: 1883-1890, 2013.

42. Yamashita S, Masuda D and Matsuzawa Y: Did we abandon probucol too soon? Curr Opin Lipidol 26: 304-316, 2015.

43. Yamashita S, Hbujo H, Arai H, Harada-Shiba M, Matsui S, Fukushima M, Saito Y, Kita T and Matsuzawa Y: Long-term probucol treatment prevents secondary cardiovascular events: A cohort study of patients with heterozygous familial hypercholesterolemia in Japan. J Atheroscler Thromb 15: 292-303, 2008.

44. Yamashita S and Matsuzawa Y: Where are we with probucol: A new life for an old drug? Atherosclerosis 207: 16-23, 2009. 